\title{
Identification of mobile lipids in human cancer tissues by ex vivo diffusion edited HR-MAS MRS
}

\author{
VALERIA RIGHI $^{1,2}$, ADELE MUCCI $^{2}$, LUISA SCHENETTI $^{2}$, ANTONELLA BACCI $^{3}$, RAFFAELE AGATI $^{3}$, \\ MARCO LEONARDI ${ }^{3}$, RICCARDO SCHIAVINA ${ }^{4}$, GIUSEPPE MARTORANA ${ }^{4}$, GIUSEPPINA LIGUORI ${ }^{5}$, \\ CARLO CALABRESE $^{5}$, ELISA BOSCHETTI ${ }^{1}$, SERGIO BONORA ${ }^{1}$ and VITALIANO TUGNOLI ${ }^{1}$ \\ ${ }^{1}$ Dipartimento di Biochimica ‘G. Moruzzi’, Università di Bologna, Via Belmeloro 8/2, 40126 Bologna; \\ ${ }^{2}$ Dipartimento di Chimica, Università di Modena e Reggio Emilia, Via G. Campi 183, 41100 Modena; \\ ${ }^{3}$ Dipartimento di Neuroscienze, Divisione e Cattedra di Neuroradiologia, Università di Bologna, Ospedale Bellaria, \\ Via Altura 3, 40139 Bologna; ${ }^{4}$ Dipartimento di Scienze Chirurgiche Specialistiche e Anestesiologiche, Sezione di Urologia, \\ Università di Bologna, Policlinico S. Orsola-Malpighi, Via P. Palagi 9; ${ }^{5}$ Dipartimento di Medicina Interna e Gastroenterologia, \\ Università di Bologna, Policlinico S. Orsola-Malpighi, Via G. Massarenti 9, 40138 Bologna, Italy
}

Received June 10, 2009; Accepted July 23, 2009

DOI: $10.3892 /$ or_00000592

\begin{abstract}
Magnetic Resonance Spectroscopy visible mobile lipids are considered important markers in the diagnosis of human cancer and are thought to be closely involved in various aspects of tumour transformation, such as cell proliferation, necrosis, apoptosis, hypoxia and drug resistance. A method allowing the straightforward identification of the lipid classes contributing to the mobile lipids in human malignant tissues is highly advisable. Ex vivo High Resolution Magic Angle Spinning Magnetic Resonance Spectroscopy was done directly on human cerebral, renal and colorectal malignant tissue specimens. A diffusion edited sequence, based on stimulated echo and bipolar gradient pulses, was used to characterize molecules with low diffusion rates, arising from mobile lipid components. Cholesterol, triglycerides and phosphatidylcholine are simultaneously detected and all contribute to the mobile lipid resonances present in malignant glioma and clear cell renal carcinoma tissue specimens spectra. On the contrary, papillary cell renal carcinoma spectrum is predominated by phosphatidylcholine resonances and that of colorectal adenocarcinoma is characterized by signals arising from triglycerides. Ex vivo diffusion edited High Resolution Magic Angle Spinning Magnetic Resonance Spectroscopy, done on intact tissue, is a powerful analytical tool to obtain a simple and immediate identification of mobile lipid components. This
\end{abstract}

Correspondence to: Dr Vitaliano Tugnoli, Dipartimento di Biochimica 'G. Moruzzi', Università di Bologna, Via Belmeloro 8/2, 40126 Bologna, Italy

E-mail: vitaliano.tugnoli@unibo.it

Key words: ex vivo, diffusion, High Resolution Magic Angle Spinning, Magnetic Resonance Spectroscopy, mobile lipids, cancer can offer a significant contribution to better understanding their involvement in cancer tissues. Furthermore, ex vivo high resolution spectroscopic measurements allow to improve the interpretation of in vivo Magnetic Resonance spectra, increasing its clinical potentiality.

\section{Introduction}

Great interest has been dedicated to Magnetic Resonance Spectroscopy (MRS) visible mobile lipids (MLs), which significance in life and death of cells has been highlighted by Hakumaki and Kauppinen (1). Lipid deposits in human cells and tissues are revealed and identified by MRS. These compounds are thought to originate mainly from triglycerides (TG) fatty acid (FA) chains with a lesser contribution from cholesteryl esters (CholE) (1). In the early 80s, Mountford and Wright hypothesized that MLs arise from neutral lipids located in plasma membrane (2). Afterwards, other authors have speculated that MLs exist in cytosolic lipid droplets (35). Several MRS studies have clearly elucidated how these lipids are closely involved in various important aspects of tumour transformation, such as cell proliferation, necrosis, apoptosis, hypoxia and drug resistance (6-10). Moreover, MLs are supposed to have clinical potential in brain cancer treatment response detection (11-14). Despite the large number of MRS studies on experimental and human cancer (1-14), the exact MLs metabolic origin is still debated, therefore, a method allowing the straightforward characterization of these important tissue components, is highly advisable. In this study, the possibility to perform the simple and simultaneous identification of cholesterol (Chol) and/or CholE, TG and phospholipids ( $\mathrm{Ph}$ ) in human malignant neoplasms, is described. Cancer tissue specimens were studied by ex vivo High Resolution Magic Angle Spinning (HR-MAS) MRS, using a diffusion edited sequence, which allowed the separation of molecules characterized by low diffusion rates. To our knowledge, a similar experiment on different human cancer tissues, has not yet been reported in literature. 


\section{Materials and methods}

Magnetic Resonance Imaging (MRI) and localized single voxel in vivo ${ }^{1} \mathrm{H}-\mathrm{MRS}$ were performed with a 3 Tesla wholebody scanner (General Electric Medical Systems, Milwaukee, WI) on two patients affected by cerebral lesion, following the routine standard clinical protocol previously described (15). After MRI and in vivo MRS the patients underwent surgery and two adjacent samples were obtained. One section was used for routine histopathology and revealed a malignant glioma in both cases. The second sample was used for HR-MAS measurements. Specimens were also collected from three patients undergoing radical nephrectomy for solid masses. Renal lesions were sorted by microscopy: two were classified as clear cell and one turned out to be a papillary cell renal carcinoma. In this study, a tissue specimen obtained from a patient who underwent surgery for colorectal adenocarcinoma has been also included. All patients gave written informed consent to participate to the study which was approved by the local research Ethics Committees.

The six tissue samples were quickly frozen in liquid nitrogen and stored at $-85^{\circ} \mathrm{C}$ until MRS analyses. Ex vivo ${ }^{1} \mathrm{H}$ HR-MAS MR spectra were recorded with a Bruker Avance400 spectrometer (Bruker BioSpin, Karlsruhe, Germany) equipped with a $4-\mathrm{mm}$ dual ${ }^{1} \mathrm{H} /{ }^{13} \mathrm{C}$ HR-MAS probe, operating at $400.13 \mathrm{MHz}$. Samples were spun at $4000 \mathrm{~Hz}$ and ${ }^{1} \mathrm{H} \mathrm{MR}$ spectra were acquired by using a sequence for diffusion measurements (16), based on stimulated echo and bipolar gradient pulses, with big delta $200 \mathrm{~ms}$, eddy current delay $\mathrm{T}_{\mathrm{e}}$ $5 \mathrm{~ms}$, little delta $2^{*} 2 \mathrm{~ms}$, fine shaped gradient with $32 \mathrm{G} / \mathrm{cm}$ followed by a $200 \mu \mathrm{sec}$ delay for gradient recovery, $8 \mathrm{kHz}$ spectral width, $8 \mathrm{k}$ data point and 256 scans. The assignments were in agreement with the literature and were confirmed by comparison of the MR spectra of Sigma standard lipid compounds [Chol, CholE, TG, phosphatidylcholine ( $\mathrm{PhC})$, saturated fatty acids and poly-unsaturated fatty acids (PUFAs)].

\section{Results and discussion}

Ex vivo HR-MAS MRS, introduced in 1997 by Cheng et al (17), has become essential to outline intact human tissues metabolic profiles $(9,18-22)$. In a previous study performed in our laboratory (22), using HR-MAS technique, we characterized the human gastric adenocarcinomas biochemical profile. In particular, a diffusion edited sequence (16) allowed us to obtain spectra displaying broad resonances of molecules characterized by low diffusion rates, deriving from mobile lipids, which were identified as saturated and unsaturated FA chains, almost exclusively esterified in TG. Since the importance of MLs in cancer (1-14), we have undertaken a diffusion edited HR-MAS MRS study on different human neoplasms, in order to indentify accurately the lipid classes contributing to the MLs resonances in human malignant tissues.

Fig. 1 shows malignant glioma ex vivo diffusion edited ${ }^{1} \mathrm{H}$ HR-MAS MR spectrum. In the window, the axial $\mathrm{T}_{2}$-wheighted MR image and localized in vivo ${ }^{1} \mathrm{H}$ MR spectrum of the same lesion, obtained before surgery, are also reported. In in vivo spectrum, two signals at 1.30 and $0.90 \mathrm{ppm}$ are present, and are assigned to methylene $-\left(\mathrm{CH}_{2}\right)_{\mathbf{n}}$ - and terminal methyl $-\mathrm{CH}_{3}$ protons, respectively, in FA chains. These signals, in brain neoplasm in vivo MR spectra, are generally attributed to the presence of FA chains arising from MLs, which are associated with tumour aggression and are considered markers of high grade malignant lesions (23); however, these resonances do not give information on the lipid classes contributing to MLs composition.

The analysis of the ex vivo diffusion edited ${ }^{1} \mathrm{H}$ HR-MAS MR spectrum is considered largely helpful. Indeed, in Fig. 1, besides several resonances pertaining to FA chains, signals arising from neutral (TG and Chol and/or CholE) and polar $(\mathrm{Ph})$ lipid moieties, are clearly observed. Eight signals [proton assignments are reported in brackets] resonating at 0.90 [terminal methyls, y- $\mathrm{CH}_{2}-\mathrm{CH}_{3}$ ], 1.30 [methylenes, $\mathrm{x}-\mathrm{CH}_{2}$ $\left(\mathrm{C}_{2}\right)_{\mathrm{n}}-\mathrm{CH}_{2}-\mathrm{y}$ and $\left.\mathrm{x}-\mathrm{C}_{2}-\left(\mathrm{CH}_{2}\right)_{\mathrm{n}}-\mathrm{C}_{2}-\mathrm{y}\right], 1.58$ [ß-methylenes, $\mathrm{x}-\mathrm{CH}_{2}-\mathrm{CH}_{2}-\mathrm{CH}_{2}-\mathrm{CO}-\mathrm{y}$ ], 2.05 [mono-allylic methylenes, $\mathrm{x}-$ $\mathrm{CH}_{2}-\mathrm{CH}=\mathrm{CH}-\mathrm{y}$ and $\left.\mathrm{x}-\mathrm{CH}_{2}-\mathrm{CH}=\mathrm{CH}-\underline{\mathrm{H}}_{2}-\mathrm{CH}_{2}-\mathrm{y}\right], 2.30[\alpha-$ methylenes, $\mathrm{x}-\mathrm{CH}_{2}-\mathrm{CH}_{2}-\mathrm{CH}_{2}-\mathrm{CO}-\mathrm{y}$ ], 2.70-2.80 [di-allylic methylenes, $=\mathrm{CH}-\underline{\mathrm{H}}_{2}-\mathrm{CH}=$ and $\left.\mathrm{x}-\mathrm{CH}=\mathrm{CH}-\left(\mathrm{CH}_{2}-\mathrm{CH}=\mathrm{CH}\right)_{\mathrm{n}}-\mathrm{y}\right]$ and 5.30 [vinyl protons, $\mathrm{x}-\mathrm{C} \underline{\mathbf{H}}=\mathrm{C} \underline{\mathbf{H}}-\left(\mathrm{CH}_{2}-\mathrm{CH}=\mathrm{C} \underline{\mathbf{H}}\right)_{\mathrm{n}}-\mathrm{y}, \mathrm{x}-\mathrm{CH}_{2}-$ $\mathrm{C} \underline{\mathbf{H}}=\mathrm{CH}-\mathrm{y}$ and $\left.\mathrm{x}-\mathrm{CH}_{2}-\underline{\mathrm{CH}}=\underline{\mathrm{H}}-\mathrm{CH}_{2}-\mathrm{CH}_{2}-\mathrm{y}\right] \mathrm{ppm}$ indicate the presence of saturated and unsaturated FA chains $(19,24,25)$. Other resonances arising from Chol and/or CholE, $\mathrm{Ph}$ and TG moieties, are detected. These lipids are clearly identified, according to the literature $(19,24,25)$ and to the comparison of single standard spectra, based on the following signals: 0.68 [Chol backbone, 18- $\mathbf{C H}_{3}$ ], 0.90 [Chol backbone, 21- $\mathbf{C H}_{3}, 9$ $\mathrm{C} \underline{\mathbf{H}}, 19-\underline{\mathrm{H}}_{3}$ ], 1.04 [Chol backbone, 1-C $\underline{\mathrm{H}}_{2}, 14-\mathrm{C} \underline{\mathbf{H}}, 17-\mathrm{C} \underline{\mathbf{H}}$,

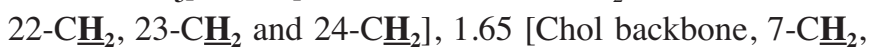
15-C $\underline{\mathbf{H}}_{2}$ and 25-C ], 3.04 [phosphatidylethanolamine (PhE) plasmalogen, $-\mathrm{CH}_{2}-\mathrm{CH}_{2}-\mathrm{NH}_{2}$ ], 3.25 [PhC, trimethyammonium, $\left.-\mathrm{N}^{+}\left(\underline{\mathrm{H}}_{3}\right)_{3}\right], 4.08$ and 4.28 [TG, bonded glycerol, $\underline{\mathrm{C}}_{2} \mathrm{OCOR}_{1}-$ $\mathrm{CHOCOR}_{2}-\underline{\mathrm{H}}_{2} \mathrm{OCOR}_{3}$ ] and 5.22 [TG, bonded glycerol, $\mathrm{CH}_{2} \mathrm{OCOR}_{1}$ - $\underline{\mathrm{H}} \mathrm{OCOR}_{2}-\mathrm{CH}_{2} \mathrm{OCOR}_{3}$ ].

Other malignant glioma ex vivo diffusion edited ${ }^{1} \mathrm{H} \mathrm{HR}-$ MAS MR spectra (data not shown) are quite similar to that reported in Fig. 1, the only difference being a more intense trimethylammonium $-\mathrm{N}^{+}\left(\mathrm{CH}_{3}\right)_{3}$ choline residue signal at $3.25 \mathrm{ppm}$, indicating a larger amount of $\mathrm{PhC}$. In both cases, diffusion edited HR-MAS sequence, due to higher signal-tonoise ratio and to the fact that signals are not spread over the whole spectrum, as in in vivo MRS, allows to determine that MR visible MLs resonances receive contribution from: i) FA esterified in TG; ii) FA esterified in PhC; iii) Chol, which has been found to be present as CholE in experimental and human gliomas (11). This opportunity appears particularly important considering, for example, that lipid content, revealed by a conventional single pulse HR-MAS MRS experiment, only from the FA signals at 1.30 and $0.90 \mathrm{ppm}$, has been found to be an important factor to separate the metastasis spectra originating from different primary tumours and was also correlated with clinical outcome (19).

All the above-mentioned lipid resonances, arising from saturated and unsaturated FA chains, TG, PhC and Chol and/or CholE moieties, are also present in Fig. 2a, displaying the clear cell renal carcinoma ex vivo diffusion edited ${ }^{1} \mathrm{H}$ HR-MAS MR spectrum. The profile of this lesion, both for signal intensities and frequencies, is very similar to the one of the other clear cell carcinoma. In the spectrum in Fig. 2a, signals arising from cholesterol backbone, which we have 


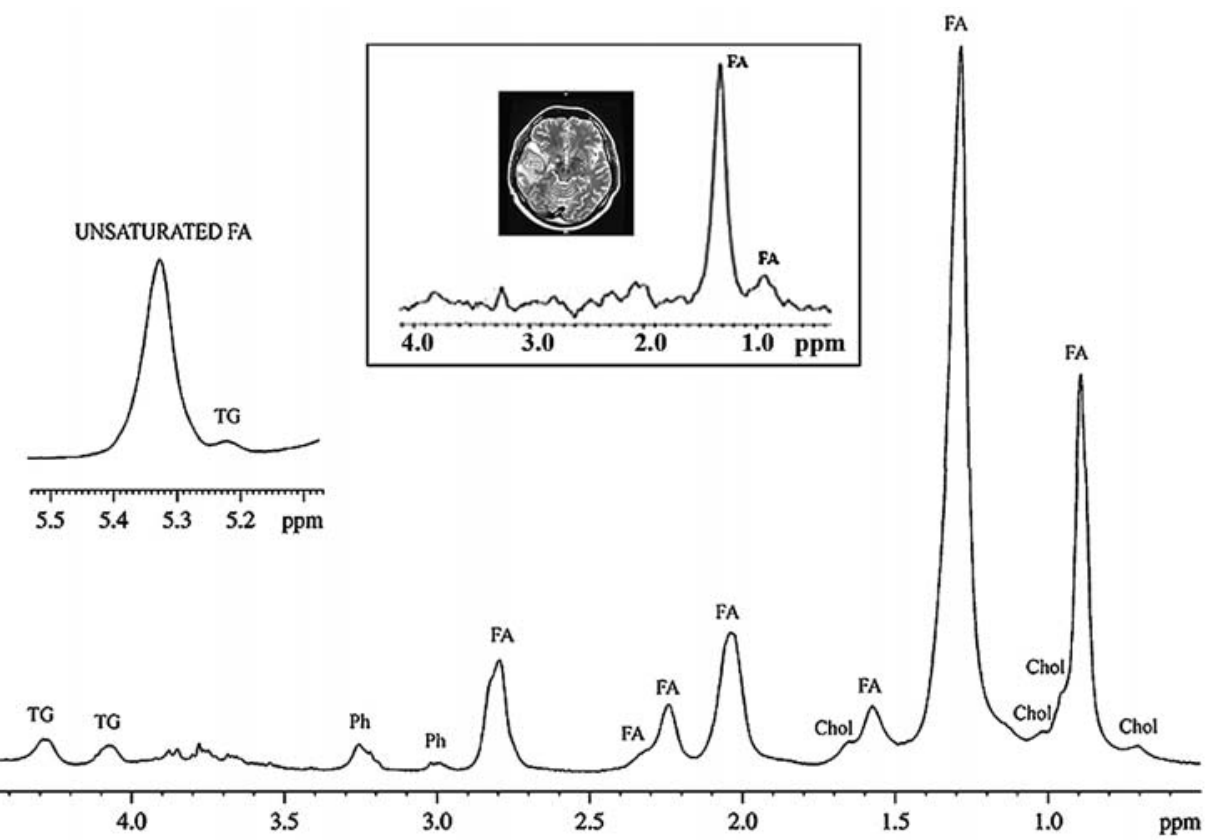

Figure 1. Ex vivo diffusion edited ${ }^{1} \mathrm{H}$ HR-MAS MR spectrum of a malignant glioma; in the window, the axial FSE $\mathrm{T}_{2}$-wheighted MR image and the localized in vivo ${ }^{1} \mathrm{H}$ MR spectrum of the same lesion, are also reported.
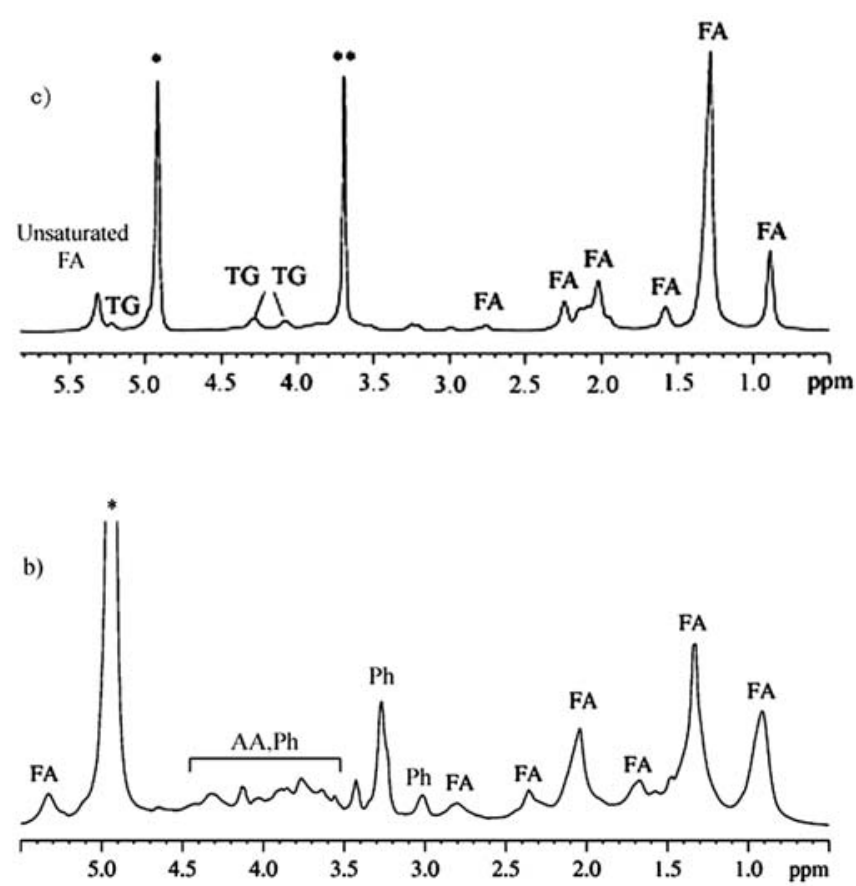

a)

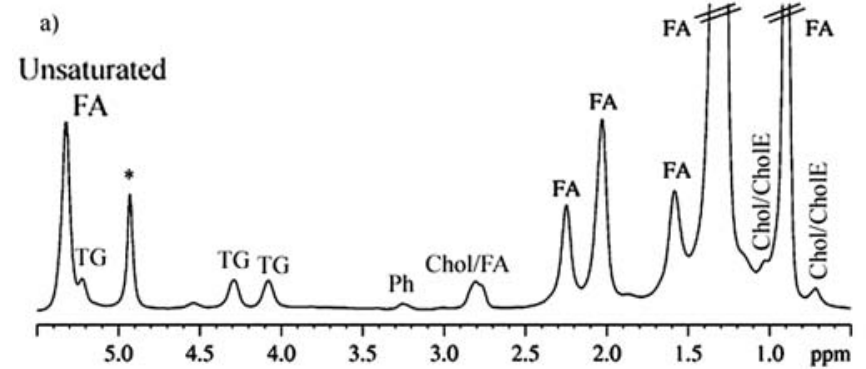

Figure 2. Ex vivo diffusion edited ${ }^{1} \mathrm{H}$ HR-MAS MR spectra of: (a) clear cell renal carcinoma; (b) papillary cell renal carcinoma; (c) colorectal adenocarcinoma; ${ }^{*}$ residual water peak; ${ }^{* *} \mathrm{PEG}$. previously found to be present as cholesteryl oleate in the chloroform/methanol extracts (26), are particularly evident. On the contrary, resonances due to Chol and/or CholE are absent, and those arising from TG are negligible, in papillary cell renal carcinoma spectrum (Fig. 2b). In fact, the diffusion edited spectrum of this lesion shows signals due to saturated and unsaturated FA chains which are esterified in $\mathrm{PhC}$, as inferred by the strong resonance at $3.25 \mathrm{ppm}$ coming up from the trimethylammonium $-\mathrm{N}^{+}\left(\mathrm{CH}_{3}\right)_{3}$ choline residue. Weak resonances in the $3.50-4.50 \mathrm{ppm}$ region are also present and assigned to bonded amino acids (AA) in small oligopeptides (22). It should be remarked that ratio between FA methyl [$\left.\mathrm{CH}_{3}\right]$ and FA methylene [- $\left.\left(\mathrm{CH}_{2}\right)_{n}{ }^{-}\right]$signal is bigger than the one present in other spectra, showing the contribution of methyl from AA in the $0.9 \mathrm{ppm}$ resonance.

Colorectal adenocarcimoma ${ }^{1} \mathrm{H}$ HR-MAS MR spectrum is reported in Fig. 2c. Signals due to saturated and unsaturated FA chains esterified in $\mathrm{TG}$, as the main lipid component characterizing the malignant tissue, are observed. On the contrary, resonances typical of $\mathrm{Ph}$ and Chol moieties are negligible or absent, respectively. The strong signal at $3.70 \mathrm{ppm}$ arises from polyethylene glycol (PEG), present in pharmaceutical preparation used for colon preparation.

As above described, a careful inspection of the human neoplastic lesions ex vivo diffusion edited HR-MAS MR spectra (Figs. 1 and 2), show clear signals arising from different groups of saturated and unsaturated FA chains. The resonance at $2.80 \mathrm{ppm}$, attributable to methylene protons between two double bonds ( $\left.=\mathrm{CH}-\mathrm{C}_{2}-\mathrm{CH}=\right)$, is particularly intense in high grade glioma spectrum (Fig. 1) and indicates the presence of PUFAs $(12,13,24,25,26)$. Monitoring these attracting markers could be of great utility. Indeed, PUFAs are strongly implicated in apoptotic processes occurring after anti-cancer gene therapy $(12,13)$ and they are supposed to have clinical potential in brain cancer treatment response detection 
(11-14). Even if TG and CholE are considered the predominant lipid groups contributing to the MRS visible MLs in human neoplastic tissue (1), from our ex vivo HR-MAS MRS findings it is evident that the contribution of mobile $\mathrm{PhC}$ cannot be overlooked.

Concluding, this preliminary study clearly indicates that diffusion edited HR-MAS MRS has the potential to bear novel implications for a better understanding of lipid biochemistry in cancer. Further studies on the direct correlation between all types of MLs components (FA, TG, Ph, Chol and/or CholE and PUFAs) characterizing human neoplastic tissues, with different aspects of tumour transformation, will be possible.

\section{Acknowledgements}

This study was supported by a grant of MUR ex $60 \%$ to V.T. and S.B.

\section{References}

1. Hakumaki JM and Kauppinen RA: ${ }^{1} \mathrm{H}$ NMR visible lipids in the life and death of cells. Trends Biochem Sci 25: 357-362, 2000.

2. Mountford CE and Wright LC: Organization of lipids in the plasma membranes of malignant and stimulated cells: a new model. Trends Biochem Sci 13: 172-177, 1988.

3. Ferretti A, Knijn A, Iorio E, et al: Biophysical and structural characterization of ${ }^{1} \mathrm{H}$-NMR-detectable mobile lipid domains in NIH-3T3 fibroblasts. Biochim Biophys Acta 1438: 329-348, 1999.

4. Pérez Y, Lahrech H, Cabañas ME, et al: Measurement by nuclear magnetic resonance diffusion of the dimensions of the mobile lipid compartment in C6 cells. Cancer Res 62: 5672-5677, 2002.

5. Iorio E, Di Vito M, Spadaro F, et al: Triacsin C inhibits the formation of ${ }^{1} \mathrm{H}$ NMR-visible mobile lipids and lipid bodies in HuT 78 apoptotic cells. Biochim Biophys Acta 1634: 1-14, 2003.

6. Zoula S, Hérigault G, Ziegler A, et al: Correlation between the occurrence of ${ }^{1} \mathrm{H}$-MRS lipid signal, necrosis and lipid droplets during C6 rat glioma development. NMR Biomed 16: 199-212, 2003.

7. Tosi MR and Tugnoli V: Cholesteryl esters in malignancy. Clin Chim Acta 359: 27-45, 2005

8. Quintero MR, Cabañas ME and Arús C: A possible cellular explanation for the NMR-visible mobile lipid (ML) changes in cultured C6 glioma cells with growth. Biochim Biophys Acta 1771: 31-44, 2007

9. Opstad KS, Bell BA, Griffiths JR, et al: An investigation of human brain tumour lipids by high-resolution magic angle spinning ${ }^{1} \mathrm{H}$ MRS and histological analysis. NMR Biomed 21: 677-685, 2008.

10. Luciani AM, Grande S, Palma A, et al: Characterization of ${ }^{1} \mathrm{H}$ NMR detectable mobile lipids in cells from human adenocarcinomas. FEBS J 276: 1333-1346, 2009.
11. Liimatainen T, Lehtimaki K, Ala-Korpela M, et al: Identification of mobile cholesterol compounds in experimental gliomas by ${ }^{1} \mathrm{H}$ MRS in vivo: Effects of ganciclovir-induced apoptosis on lipids. FEBS Lett 580: 4746-4750, 2006.

12. Hakumäki JM, Poptani H, Sandmair AM, et al: ${ }^{1} \mathrm{H}$ MRS detects polyunsaturated fatty acid accumulation during gene therapy of glioma: implications for the in vivo detection of apoptosis. Nat Med 5: 1323-1327, 1999 .

13. Griffin JL, Lehtimäki KK, Valonen PK, et al: Assignment of ${ }^{1} \mathrm{H}$ nuclear magnetic resonance visible polyunsaturated fatty acids in BT4C gliomas undergoing ganciclovir-thymidine kinase gene therapy-induced programmed cell death. Cancer Res 63: 3195-3201, 2003.

14. Liimatainen T, Hakumäki JM, Kauppinen RA, et al: Monitoring of gliomas in vivo by diffusion MRI and ${ }^{1} \mathrm{H}$ MRS during gene therapy-induced apoptosis: interrelationships between water diffusion and mobile lipids. NMR Biomed 22: 272-279, 2009.

15. Ricci R, Bacci A, Tugnoli V, et al: Metabolic findings on 3T ${ }^{1} \mathrm{H}-\mathrm{MR}$ spectroscopy in peritumoral brain edema. Am J Neuroradiol 28: 1287-1291, 2007.

16. Wu D, Chen A and Johnson CS Jr: An improved diffusion ordered spectroscopy experiment incorporating bipolar gradient pulses. Magn Reson Series A 115: 260-264, 1995.

17. Cheng LL, Ma MJ, Becerra L, et al: Quantitative neuropathology by high resolution magic angle spinning proton magnetic resonance spectroscopy. Proc Natl Acad Sci USA 94: 6408-6413, 1997.

18. Calabrese C, Pisi A, Di Febo G, et al: Biochemical alterations from normal mucosa to gastric cancer by ex vivo magnetic resonance spectroscopy. Cancer Epidemiol Biom Prev 17: 1386-1395, 2008.

19. Sjobakk TE, Johansen R, Bathen TF, et al: Characterization of brain metastases using high-resolution magic angle spinning MRS. NMR Biomed 21: 175-185, 2008.

20. Chan EC, Koh PK, Mal M, et al: Metabolic profiling of human colorectal cancer using high-resolution magic angle spinning nuclear magnetic resonance (HR-MAS NMR) spectroscopy and gas chromatography mass spectrometry (GC/MS). J Proteome Res 8: 352-361, 2009

21. Wilson M, Davies NP, Grundy RG, et al: A quantitative comparison of metabolite signals as detected by in vivo MRS with ex vivo ${ }^{1} \mathrm{H}$ HR-MAS for childhood brain tumours. NMR Biomed 22: $213-219,2009$

22. Tugnoli V, Mucci A, Schenetti L, et al: Ex vivo HR-MAS Magnetic Resonance Spectroscopy of human gastric adenocarcinomas: A comparison with healthy gastric mucosa. Oncol Rep 16: 543-553, 2006.

23. Preul MC, Caramanos Z, Collins DL, et al: Acccurate, non invasive diagnosis of human brain tumors by using proton magnetic resonance spectroscopy. Nat Med 2: 323-325, 1996

24. Tugnoli V, Tosi MR, Tinti A, et al: Characterization of lipids from human brain tissues by multinuclear magnetic resonance spectroscopy. Biopolymers 62: 297-306, 2001.

25. Subramanian A, Shankar Joshi B, Roy AD, et al: NMR spectroscopic identification of cholesterol esters, plasmalogen and phenolic glycolipids as fingerprint markers of human intracranial tuberculomas. NMR Biomed 21: 272-288, 2008.

26. Tugnoli V, Bottura G, Fini G, et al: ${ }^{1} \mathrm{H}-\mathrm{NMR}$ and ${ }^{13} \mathrm{C}-\mathrm{NMR}$ lipid profiles of human renal tissues. Biopolymers 72: 86-95, 2003. 